\title{
CHRONIC OBSTRUCTIVE PULMONARY DISEASE
}

\section{Imbalance between levels of nitrogen oxides and peroxynitrite inhibitory activity in chronic obstructive pulmonary disease}

\author{
H Kanazawa, S Shiraishi, K Hirata, J Yoshikawa
}

See end of article for authors' affiliations

\section{Correspondence to:} Dr H Kanazawa,

Department of Respiratory Medicine, Graduate School of Medicine, Osaka City University,

1-4-3 Asahi-machi, Abenoku, Osaka

545-8585, Japan;

kanazawa-h@

Imed.osaka-cu.ac.jp

Revised version received 14 September 2002

Accepted for publication 12 October 2002

\begin{abstract}
Background: The prevalent theory concerning the pathogenesis of chronic obstructive pulmonary disease (COPD) is of an imbalance between oxidants and antioxidants in the lung. It has recently been reported that the production of peroxynitrite, an extremely potent oxidant, is increased in the airways of patients with COPD. A study was undertaken of the imbalance between the levels of nitrogen oxides and antioxidant activity against peroxynitrite in the airways of patients with COPD.

Methods: Sputum induction was performed in 30 patients with COPD and 15 normal control subjects. Levels of nitrogen oxides, percentage of neutrophils, and interleukin 8 (IL-8) levels were measured in sputum samples, and peroxynitrite inhibitory activity was assayed by monitoring rhodamine formation. Results: Nitrite and nitrate levels in induced sputum were significantly higher in patients with COPD than in normal controls (949 (133) $\mu M v 621$ (89) $\mu M, p<0.001)$. In contrast, peroxynitrite inhibitory activity in induced sputum was significantly lower in patients with COPD than in normal controls (47.4 $(12.7) \% \vee 92.9(3.9) \%, p<0.001)$. There was a negative correlation between nitrite and nitrate levels and peroxynitrite inhibitory activity in induced sputum $(r=-0.775, p<0.001)$. Peroxynitrite inhibitory activity was also significantly correlated with forced expiratory volume in 1 second $\left(F E V_{1}\right) \%$ predicted $(r=0.539, \mathrm{p}=0.004), \mathrm{FEV}_{1} / \mathrm{FVC}(r=0.512, \mathrm{p}=0.006)$, and carbon monoxide transfer factor (TLCO) $(r=0.486, p=0.009)$. Moreover, there was a significant negative correlation between peroxynitrite inhibitory activity and the degree of neutrophilic inflammation (percentage of neutrophils: $r=-0.754$, $p<0.001$; IL-8 levels: $r=-0.497, p=0.007$ ).

Conclusions: Reduced peroxynitrite inhibitory activity and increased levels of nitrogen oxides are found in induced sputum from patients with COPD. An imbalance in nitrogen oxides and antioxidant defence may contribute to the pathogenesis of COPD.
\end{abstract}

that the thin layer of epithelial lining fluid (ELF) may provide antioxidant protection against peroxynitrite and serve as a front line defence for airway epithelial cells. ${ }^{89}$ The major antioxidants in ELF are based on thiols which may function as antioxidants against peroxynitrite in the respiratory tract. We have therefore measured total antioxidant activity against peroxynitrite to examine the physiological effects of peroxynitrite in the airways of patients with COPD and to determine whether there is an imbalance between levels of nitrogen oxides and antioxidant activity against peroxynitrite in the airways of these patients.

\section{METHODS}

\section{Subjects}

Thirty patients with COPD who satisfied the American Thoracic Society criteria ${ }^{10}$ were randomly enrolled from the respiratory outpatient clinic of our institution. They had a history of former smoking ( $>20$ pack years) and irreversible airflow limitation (reversibility $<10 \%$ predicted forced expiratory volume in $\mathrm{l}$ second $\left(\mathrm{FEV}_{1}\right)$ after $200 \mu \mathrm{g}$ inhaled salbutamol). Their regular medication consisted of theophylline and an inhaled anticholinergic drug, but none had received oral or inhaled corticosteroids. They received no medication during the spirometric study and sputum induction. All patients were clinically stable and none had a history of respiratory infection for at least 4 weeks before the study. Fifteen healthy lifelong non-smoking volunteers of mean age 58.5 years with no history of lung disease $\left(\mathrm{FEV}_{1} 99.5 \%\right)$ formed a control group. 
Table 1 Clinical characteristics of study subjects

\begin{tabular}{|c|c|c|}
\hline & Normal controls & COPD patients \\
\hline Subject number (M/F) & $15(12 / 3)$ & $30(25 / 5)$ \\
\hline Age (years) & $58.5(5.5)$ & $62.4(4.5)$ \\
\hline $\mathrm{FEV}_{1}$ (\% predicted) & $99.5(4.5)$ & $52.1(13.8)^{*}$ \\
\hline $\mathrm{FEV}_{1} / \mathrm{FVC}(\%)$ & $90.4(2.5)$ & $44.2(8.3)^{*}$ \\
\hline TLCO (\%) & ND & $43.3(9.4)$ \\
\hline \multicolumn{3}{|l|}{ Sputum } \\
\hline$\%$ neutrophils & 22.3 (3.9) & $57.2(10.9)^{*}$ \\
\hline IL-8 (ng/ml) & $0.88(0.35)$ & $8.08(3.80)^{*}$ \\
\hline \multicolumn{3}{|c|}{$\begin{array}{l}\text { Values are mean }(S D) \text {. } \\
\mathrm{FEV}_{1}=\text { forced expiratory volume in } 1 \text { second; } F V C=\text { forced vital } \\
\text { capacity; TLCO=carbon monoxide transfer factor; } N D=\text { not determined. } \\
{ }^{*} p<0.001 \text { compared with normal controls. }\end{array}$} \\
\hline
\end{tabular}

All subjects gave their written informed consent for participation in the study which was approved by the ethics committee of Osaka City University.

\section{Sputum induction and processing}

Spirometric tests were performed before inhalation of $200 \mu \mathrm{g}$ salbutamol via a metered dose inhaler. All subjects were instructed to wash their mouth thoroughly with water. They then inhaled 3\% saline at room temperature, nebulised via an ultrasonic nebuliser (NE-U12, Omron Co, Tokyo, Japan) at maximum output. They were encouraged to cough deeply at 3 minute intervals thereafter. The spirometric tests were repeated after sputum induction. If the $\mathrm{FEV}_{1}$ fell, the subjects were required to wait until it returned to the baseline value. The sputum sample diluted with phosphate buffer solution (PBS) containing dithiothreitol (final concentration $1 \mathrm{mmol} /$ 1) was then centrifuged at $400 \mathrm{~g}$ for 10 minutes and the cell pellet was resuspended. Total cell counts were performed with a haemocytometer and slides were made by using a cytospin (Cytospin 3; Shandon, Tokyo, Japan) and stained with May-Grunwald-Giemsa stain for differential cell counts. The supernatant was stored at $-70^{\circ} \mathrm{C}$ for subsequent assay for interleukin 8 (IL-8), nitrite, and nitrate levels.

The IL-8 concentration was measured using an enzyme immunoassay kit (Amersham, UK). Nitrite and nitrate levels in induced sputum were assayed colorimetrically after the Griess reaction as previously described..$^{11} 200 \mu \mathrm{l}$ of the sputum sample or standard was deproteinated by adding $20 \mu \mathrm{l} \mathrm{NaOH}$ ( $1.0 \mathrm{~mol} / \mathrm{l}$ at $4^{\circ} \mathrm{C}$; Wako Chemical Co, Osaka, Japan) and $30 \mu \mathrm{l}$ $\mathrm{ZnSO}_{4}\left(1.3 \mathrm{~mol} / \mathrm{l}\right.$ at $4^{\circ} \mathrm{C}$; Wako Chemical Co). Samples were mixed and allowed to stand on ice for 15 minutes. After centrifugation $\left(5\right.$ minutes at $\left.4^{\circ} \mathrm{C}, 2600 \mathrm{~g}\right), 100 \mu \mathrm{l}$ of supernatant was mixed with $5 \times 10^{-2}$ units nitrate reductase (Sigma Chemical Co), $20 \mu \mathrm{l}$ of $0.2 \mathrm{~mol} / \mathrm{l} \mathrm{N}$-tris (hydroxymethyl) methylamino enthanesulphonic acid ( $\mathrm{pH}$ 7.0, Sigma Chemical $\mathrm{Co}$ ), and $20 \mu \mathrm{l}$ of $0.5 \mathrm{~mol} / \mathrm{l}$ sodium formate (Wako Chemical
Co). After anaerobic incubation at room temperature for 20 minutes, $1.0 \mathrm{ml}$ water was added to the samples and nitrite was assayed in supernatants obtained by centrifugation $(5$ minutes, $260 \mathrm{~g})$. Deproteinated samples or standards $(200 \mu \mathrm{l})$ were mixed with $20 \mu \mathrm{l}$ of $1 \%$ sulfanilamide (Sigma Chemical Co) in $15 \%$ phosphoric acid (Wako Chemical Co). After 10 minutes, $20 \mu \mathrm{l}$ of $0.1 \% \mathrm{~N}$-(1-naphthyl) ethylenediamine (Sigma Chemical Co) was added and the absorption at $540 \mathrm{~nm}$ was determined. We chose to use the sol phase of sputum for the measurement of peroxynitrite inhibitory activity to avoid the potential confounding influence of DTT, as described in our recent study. ${ }^{12}$ The sol phase was obtained by ultracentrifuging the remaining portion of the sputum sample at $60000 \mathrm{~g}$ for 60 minutes at $4^{\circ} \mathrm{C}$. This was allocated and stored at $-70^{\circ} \mathrm{C}$ for subsequent assay for peroxynitrite inhibitory activity.

All subjects produced an adequate specimen of sputum; a sample was considered adequate if the patient was able to expectorate at least $2 \mathrm{ml}$ of sputum and if, on differential cell counting, the slides contained $<10 \%$ squamous cells.

\section{Measurement of peroxynitrite inhibitory activity}

Working solutions of peroxynitrite (Wako Pure Chemical Industries Ltd, Osaka, Japan) were prepared by dilution in $0.1 \mathrm{~N} \mathrm{NaOH}$ just before use as $10^{-2} \mathrm{~mol} / \mathrm{l}$ solutions and further dilutions were made in PBS. The peroxynitrite concentration was determined spectrophotometrically by measuring the absorption at $302 \mathrm{~nm}\left(\epsilon \mathrm{M}=1670 \mathrm{M}^{-1} \mathrm{~cm}^{-1}\right)$. Peroxynitrite readily oxidises dihydrorhodamine- $123 .{ }^{13} \mathrm{~A}$ standard curve of oxidising activity of dihydrorhodamine- 123 to rhodamine was constructed using peroxynitrite. Peroxynitrite inhibitory activity was assayed by monitoring rhodamine formation at $500 \mathrm{~nm}$ in reaction mixtures containing $200 \mu \mathrm{l}$ sputum sample, $1.3 \mathrm{ml}$ dihydrorhodamine- 123 diluted with PBS (pH 7.4 ), and $500 \mu \mathrm{l}$ peroxynitrite for 30 minutes at $37^{\circ} \mathrm{C}^{14}{ }^{15}$ Peroxynitrite inhibitory activity was assayed in at least triplicate, and our recent data supported the specificity of this assay system for peroxynitrite. ${ }^{16}$

\section{Statistical analysis}

All values are presented as mean (SD). Differences between groups are presented as mean differences with $95 \%$ confidence intervals (CI). Student's $t$ test and Mann-Whitney U test were used to compare group means, and differences in variance were tested using the F test. The significance of correlations was evaluated by determining Spearman rank correlation coefficients. A p value of $<0.05$ was considered significant.

\section{RESULTS}

The clinical characteristics of the 30 patients with COPD and 15 age matched normal controls are shown in table 1. All patients with COPD had significant airflow obstruction and decreased levels of TLCo. The percentage of neutrophils and
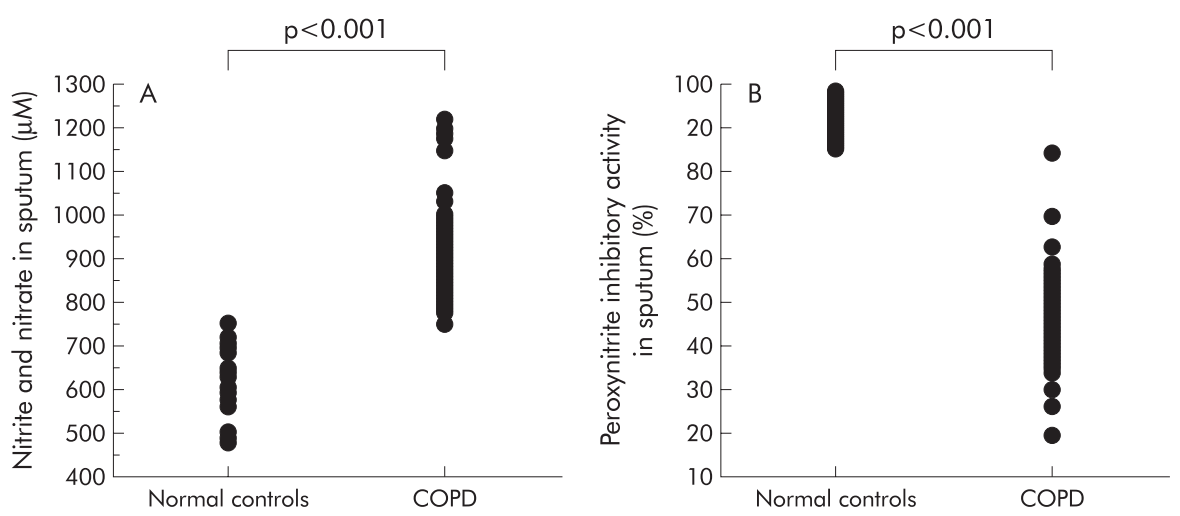

Figure 1 (A) Nitrite and nitrate levels and (B) peroxynitrite inhibitory activity in induced sputum in patients with COPD and normal controls. 


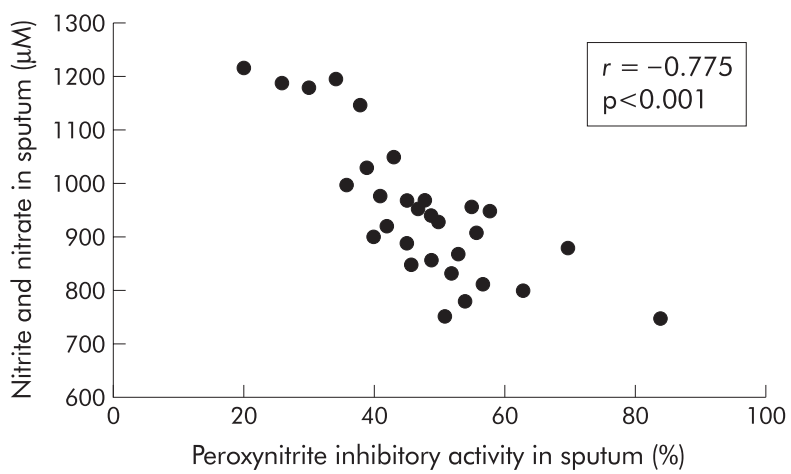

Figure 2 Correlation between nitrite and nitrate levels and peroxynitrite inhibitory activity in induced sputum.

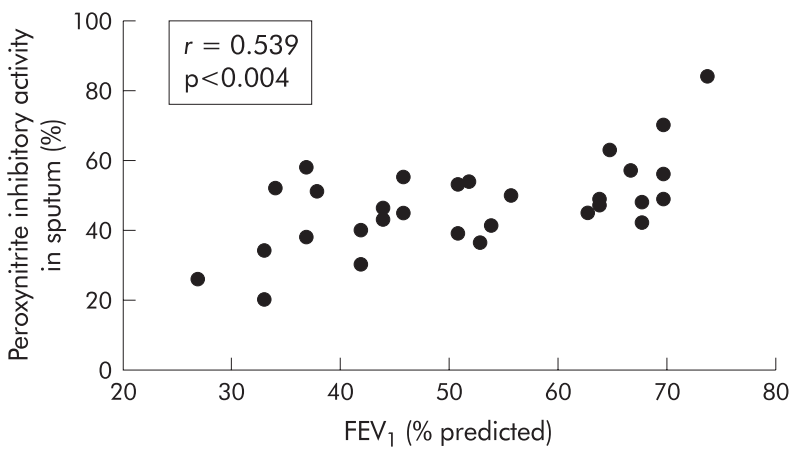

Figure 3 Correlation between peroxynitrite inhibitory activity in induced sputum and FEV $1 \%$ predicted).

concentration of IL-8 in induced sputum were significantly higher in patients with COPD than in normal control subjects (\% neutrophils: mean difference $-34.9 \%, 95 \%$ CI of difference -40.8 to $-29.0, \mathrm{p}<0.001$; IL-8: mean difference $-7.2 \mathrm{ng} / \mathrm{ml}$, 95\% CI of difference -9.1 to $-5.2, \mathrm{p}<0.001$ ).

Nitrite and nitrate levels in induced sputum were significantly higher in patients with COPD than in normal controls (949 (133) $\mu \mathrm{M} v 621$ (89) $\mu \mathrm{M}$; mean difference $-328 \mu \mathrm{M}, 95 \%$ CI of difference -404 to $-251, p<0.001$; fig $1 \mathrm{~A})$. In contrast, peroxynitrite inhibitory activity in induced sputum was significantly lower in patients with COPD than in normal controls (47.4 (12.7)\% v 92.9 (3.9)\%; mean difference 45.5\%, 95\% CI of difference 38.8 to $52.4 \%, \mathrm{p}<0.001$; fig $1 \mathrm{~B}$ ), and there was a negative correlation between nitrite and nitrate levels and peroxynitrite inhibitory activity in induced sputum $(r=-0.775$, $\mathrm{p}<0.001$; fig 2). Peroxynitrite inhibitory activity was also significantly correlated with $\mathrm{FEV}_{1} \%$ predicted $(r=0.539$, $\mathrm{p}=0.004), \mathrm{FEV}_{\mathrm{1}} / \mathrm{FVC}(r=0.512, \mathrm{p}=0.006)$, and TLCo $(r=0.486$, $\mathrm{p}=0.009$; fig 3 ). Moreover, there was a significant negative correlation between peroxynitrite inhibitory activity and the percentage of neutrophils in induced sputum $(r=-0.754$, $\mathrm{p}<0.001$; fig 4), and a negative correlation was also found between peroxynitrite inhibitory activity and the concentration of IL-8 in induced sputum ( $r=-0.497, \mathrm{p}=0.007$; fig 5 ).

\section{DISCUSSION}

In the present study peroxynitrite inhibitory activity was assayed by monitoring rhodamine formation. The oxidation of dihydrorhodamine-123 to rhodamine is mediated by peroxynitrite but not by superoxide anion, $\mathrm{H}_{2} \mathrm{O}_{2}$, or NO. Using this method, we found that peroxynitrite inhibitory activity in induced sputum was significantly lower in patients with COPD than in normal controls, and that its activity was correlated with $\mathrm{FEV}_{1}, \mathrm{FEV}_{1} / \mathrm{FVC}$, and TLCo. We also found that peroxynitrite inhibitory activity was inversely correlated with the

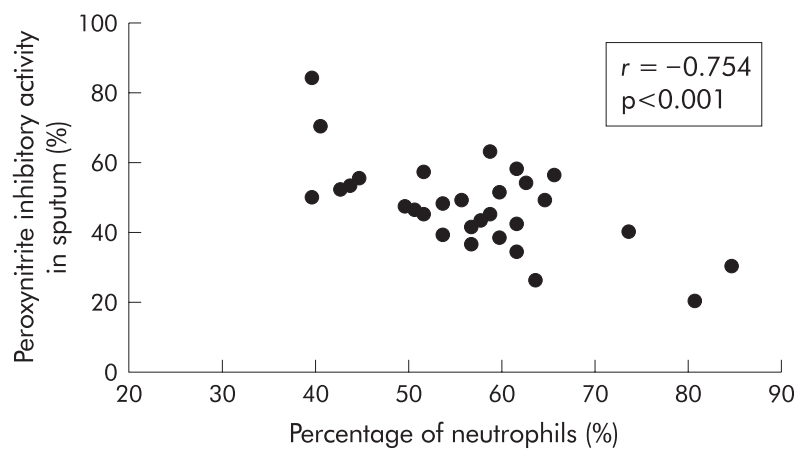

Figure 4 Correlation between peroxynitrite inhibitory activity and percentage of neutrophils in induced sputum.

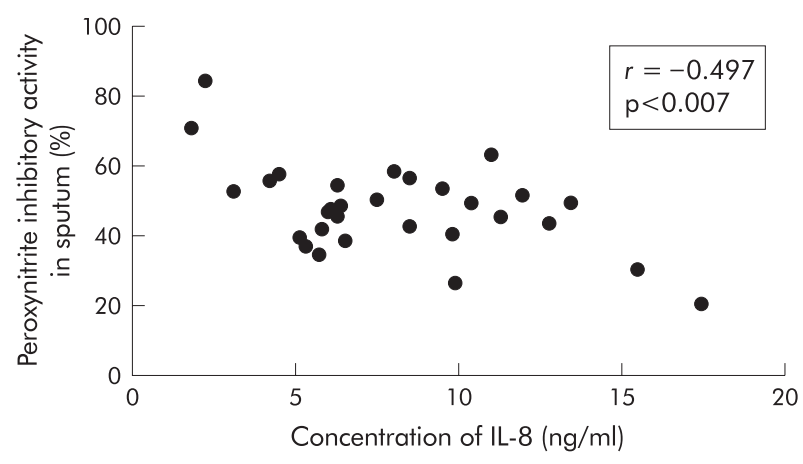

Figure 5 Correlation between peroxynitrite inhibitory activity and concentration of IL-8 in induced sputum.

percentage of neutrophils and IL-8 levels in induced sputum in patients with COPD. IL-8 is a cytokine synthesised by various cells including macrophages and neutrophils, and a potent activator of neutrophils. IL-8 induces superoxide anion release from neutrophils in vitro, and intravenous administration of IL-8 in vivo has been reported to induce accumulation of neutrophils in the lung. ${ }^{17}$ The expression of IL-8 by various cells in the airways may therefore be critically important in the pathogenesis of COPD. In an earlier study we found that IL-8 levels were significantly higher in patients with COPD than in normal controls, and that IL-8 levels were correlated with the degree of annual decline in $\mathrm{FEV}_{1}$ in COPD.$^{18}$ Moreover, a previous report suggested that airway obstruction and rapid decline in lung function are associated with an increased number of neutrophils in the sputum of smokers. ${ }^{19}$ Although prevailing theories for the pathogenesis of COPD have focused on smoking induced production of proteolytic enzymes and oxidants from neutrophils stimulated by IL-8, we found that neutrophilic inflammation was inversely correlated with antioxidant activity against peroxynitrite in the airways of patients with COPD.

Because oxidants play a pronounced role in cigarette smoke induced lung damage, the status of pulmonary antioxidant defence mechanisms assumes paramount importance. However, there is limited information on the antioxidant defences of ELF in smokers and even less for patients with COPD. Moreover, a notable inconsistency exists, and the findings are difficult to compare because of the different designs of the various studies. One study found that cigarette smoking was associated with decreased plasma ascorbate, $\beta$-carotene, and vitamin E levels. ${ }^{20}$ In addition, vitamin E levels were lower in the lung lavages of young asymptomatic smokers. ${ }^{21}$ On the other hand, a number of studies have reported increased antioxidants in cigarette smokers-for example, levels of vitamins $\mathrm{C}$ and $\mathrm{E}$ were higher in the plasma of cigarette smokers than in non-smokers. ${ }^{22}$ Additional endogenous mechanisms may 
increase antioxidant levels in certain smokers. In this regard, certain smokers had increased glutathione (GSH) and GSH peroxidase activities in their ELF compared with nonsmokers. ${ }^{23}$ Thus, there are apparent discrepancies between these studies of antioxidants in ELF.

Airway inflammation seems to play an important role in the pathogenesis of COPD, and it has been shown that the production of superoxide anion and NO by airway inflammatory cells is increased in patients with COPD. ${ }^{24}$ The existing evidence suggests that peroxynitrite is formed in the respiratory tract of these patients, although the cellular source of peroxynitrite in the airways of patients with COPD is unclear. A previous study showed that the production of peroxynitrite was increased in airway macrophages and neutrophils in patients with COPD compared with normal control subjects. ${ }^{25}$ On the other hand, the reaction of peroxynitrite with airway thiols (RSH) is associated with oxidation of RSH to the corresponding disulfide (RSSR). The method used in this study therefore evaluates the reduced form antioxidants against peroxynitrite. Indeed, it is important to emphasise that local antioxidant defences in patients with COPD is mediated by only the reduced form antioxidants. It seems likely that a balance exists between peroxynitrite generation and antioxidant defences to maintain normal airway function. When the balance is shifted towards increased peroxynitrite generation, the reduced form antioxidants are diminished and therefore the airways have markedly increased susceptibility to peroxynitrite. We have clearly shown that reduced peroxynitrite inhibitory activity is likely to reflect the increases in nitrogen oxides in the airways of patients with COPD.

The novel aspect of this investigation is the finding of reduced peroxynitrite inhibitory activity and increased levels of nitrogen oxides in induced sputum in patients with COPD. This imbalance in nitrogen oxides and antioxidant defence may contribute to the pathogenesis of COPD.

\section{ACKNOWLEDGEMENT}

This work was supported by grant-in-aid for Scientific Research (13670611) from the Ministry of Education, Science and Culture, Japan.

\section{Authors' affiliations}

H Kanazawa, S Shiraishi, K Hirata, J Yoshikawa, Department of Respiratory Medicine, Graduate School of Medicine, Osaka City University, Osaka, Japan

\section{REFERENCES}

1 Taylor JC, Madison R, Kosinska D. Is antioxidant deficiency related to chronic obstructive disease? Am Rev Respir Dis 1986;134:285-9.

2 Beckman JS, Beckman TM, Chen J, et al. Apparent hydroxyl radical production by peroxynitrite: implication for endothelial injury from nitric oxide and superoxide. Proc Natl Acad Sci USA 1990;87:1620-4.

3 Beckman JS. Reactions between nitric oxide, superoxide, and peroxynitrite: footprints of peroxynitrite in vivo. Adv Pharmacol 1995;34:17-43.
4 Okamoto T, Akaike T, Nagano T, et al. Activation of human neutrophil procollagenase by nitrogen dioxide and peroxynitrite: a novel mechanism for procollagenase activation involving nitric oxide. Arch Biochem Biophys 1997;342:261-74.

5 Corradi M, Montuschi P, Donnelly LE, et al. Increased nitrosothiols in exhaled breath condensate in inflammatory airway diseases. Am J Respir Crit Care Med 2001;163:854-8

6 Postma DS, Renkema TEJ, Noordhoek JA, et al. Association between nonspecific bronchial hyperreactivity and superoxide anion production by polymophonuclear leukocytes in chronic airflow obstruction. Am Rev Respir Dis 1988; 137:57-61.

7 Kanazawa H, Shoji S, Yoshikawa T, et al. Increased production of endogenous nitric oxide in patients with bronchial asthma and chronic obstructive pulmonary disease. Clin Exp Allergy 1998;10:1244-50.

8 Cantin AM, Fells GA, Hubbard RC, et al. Antioxidant macromolecules in the epithelial lining fluid of the normal human lower respiratory tract. $J$ Clin Invest 1990;86:962-71

9 Pacht ER, Davis WB. Role of transferrin and ceruloplasmin in antioxidant activity of lung epithelial lining fluid. J Appl Physiol 1988;64:2092-9.

10 American Thoracic Society. Standards for the diagnosis and care of patients with chronic obstructive pulmonary disease (COPD) and asthma. Am Rev Respir Dis 1987;136:225-44.

11 Phizackerley PJR, Al-Dabbagh SA. The estimation of nitrate and nitrite in saliva and urine. Anal Biochem 1983:131:242-5.

12 Kanazawa H, Shiraishi S, Hirata K, et al. Decreased peroxynitrite inhibitory activity in induced sputum in patients with bronchial asthma. Thorax 2002;57:509-12.

13 Crow JP, Beckman JS, McCord JM. Sensitivity of the essential zinc-thiolate moiety of yeast alcohol dehydrogenase to hypochlorite and peroxynitrite. Biochemistry 1995;34:3544-52.

14 Szabo C, Salzman AL, Ischiropoulos H. Peroxynitrite-mediated oxidation of dihydrorhodamine 123 occurs in early stages of endotoxic and hemorrhagic shock and ischemia-reperfusion injury. FEBS Lett 1995;372:229-32.

15 Owens MW, Milligan SA, Jourd'heuil D, et al. Effects of reactive metabolites of oxygen and nitrogen on gelatinase A activity. Am J Physiol 1997;273:L445-50

16 Kanazawa H, Hirata K, Yoshikawa J. Possible mechanism of bronchoconstriction by SIN-1 in anaesthetized guinea pigs: roles of nitric oxide and peroxynitrite. Clin Exp Allergy 2000;30:445-50.

17 Peveri $\mathbf{P}$, Walz A, Dewald B, et al. A neutrophil-activating factor produced by human mononuclear phagocytes. J Exp Med 1988:167:1547-59.

18 Kanazawa H, Kurihara N, Otsuka T, et al. Clinical significance of serum concentration of interleukin-8 in patients with bronchial asthma or chronic pulmonary emphysema. Respiration 1996;63:236-40.

19 Stanescu D, Sanna A, Veriter C, et al. Airway obstruction, chronic expectoration, and rapid decline of $\mathrm{FEV}_{1}$ in smokers are associated with increased levels of sputum neutrophils. Thorax 1996;51:267-71.

20 Anderson R. Assessment of the roles of vitamin $C$, vitamin $E$, and $\beta$-carotene in the modulation of oxidant stress mediated by cigarette smoke activated phagocytes. Am J Clin Nutr 1991;53:358-61.

21 Kondo T, Tsugami S, Yoshioka A, et al. Current smoking of elderly men reduces antioxidants in alveolar macrophages. Am J Respir Crit Care Med 1994;149:178-82

22 Mezzetti A, Lapenna D, Pierdomenico SD, et al. Vitamins E, C and lipid peroxidation in plasma and arterial tissues of smokers and non-smokers. Atherosclerosis 1995;112:91-9.

23 Cantin AM, North SL, Hubbard RC, et al. Normal alveolar epithelia lining fluid contains high levels of glutathione. J Appl Physiol 1989;63:152-7.

24 Schaberg $T$, Haller $H$, Rau $M$, et al. Superoxide anion release induced by platelet-activating factor is increased in human alveolar macrophages from smokers. Eur Respir J 1992;5:3877-93.

25 Ichinose $M$, Sugiura $H$, Yamagata $S$, et al. Increase in reactive nitrogen species production in chronic obstructive pulmonary disease. Am J Respir Crit Care Med 2000;162:701-6. 